\title{
Capital Punishment of Minors
}

John MacKenzie

I

was watching "Politically Incorrect" the other day and while I usually

enjoy the show for the diversity of opinions it offers, I cannot help but be angered and often grimly amused at some of them. This time the discussion focused around the question of capital punishment of minors. Personally I feel that any form of capital punishment is a disgrace to the society that practices it, but capital punishment of minors is especially abhorrent. Bill Maher made what must be the most shocking statement I have heard in a long time when he quipped, "We have to get over our squeamishness about killing minors!"

Squeamishness? Not exactly the adjective I choose to describe our aversion to killing children. One of his guests, a woman simply named "Kennedy" and billed as a "cultural icon/activist," commented that "we" (meaning Americans) should "just fry the little bastards." She applied the reasoning that if kids are killing at nine or ten, then what would they be doing when they are twenty? By that well-reasoned line of thinking we should just enact the death penalty for, say, stealing candy or jaywalking (I think Texas is already working on this).

It is interesting to note that the catalyst of this conversation was the arrest and arraignment of a seven-year-old and a nine-year-old in Chicago last year for rape and murder. Less than two weeks after their arrest, they were released because exculpatory evidence had cleared them, including what was described as "inappropriate coercion" by the investigating officers during interrogation. From the moment the case hit the press my keen insight and sharp intellect posed the question: "How the hell does a kid who has yet to reach puberty commit rape?" I guess that rather obscure point escaped the seasoned and skilled investigators of the Chicago Police Department.

More disturbing than the fact that more people seem concerned with fixing blame than fixing the problem is the logic of proposed remedies. Blame-masters point their bony fingers at video games, the media, parents, the internet and just about everything and anyone who seems convenient. They see the violence in our society and by some bizarre logic think that more violence is the solution. I see a society that appears to have lost compassion. Sure, we have compassion for the underprivileged, for the handicapped, for the helpless - it is easy and natural to feel compassion for the helpless and the cute. This is not the compassion we need to cultivate. 
As a society, compassion is not a convenience; it is a necessity. Real compassion costs. We need a society that extends compassion when it is difficult to do so. That is civilization.

When I caught the media blitz surrounding the Columbine shootings, ${ }^{1}$ I was almost numbed by the tragedy of it. So many lives lost for no apparent reason, including those of the two shooters Klebold and Harris. Other than the odd exception, few people seem able to grasp the idea that feeling compassion for victims and perpetrators is not an exclusive choice. They were all children and while we can all feel compassion for the victims, that compassion costs nothing and requires little effort. It is certainly not a sign that we have advanced as a civilization in the last few thousand years, and compared to other societies we seem to have fallen far behind.

How about some compassion that costs, a compassion that forces us to recognize that when a society starts to experience widespread and severe problems we all have a share of the blame for those problems. As a society we must assume some measure of responsibility and acknowledge that we have a long way to go before we can begin pointing our collective fingers at individuals.

We force feed our children a diet of mindless videocy ${ }^{2}$ and if little Billy is not watching wrestling then he is catching the latest thermal bombsight image delivered in real time as the JDAM GBU ${ }^{3}$ gently glides its high explosive warhead into the latest enemy (or oops, the Chinese Embassy). Hey, let us watch a first class demonstration of all those thinking errors they teach us at RHC (the Regional Health Centre). Blaming others: "if the DMA ${ }^{4}$ had maps up to date;" minimization: "civilian casualties were minimal;" rationalization: "in war nothing is perfect;" and justification: "if they [place Rogue Nation of your choice here] had done as we told them we would not be dropping bombs on them." The pros on CNN who earn six figures per year can justify anything. Let us see if Billy understands what "collateral damage" means.

Perhaps our kids are starting to understand that if a cluster bomb is good enough for the government to cure its indignation with enemies, then perhaps

1 On April 26, 1999, two students (Dylan Kebold and Eric Harris) at Columbine High School in Colorado opened fire in the school killing twelve students and one teacher, before killing themselves.

2 The numbing of consciousness by addiction to television.

3 Joint Direct Attack Munition Guided Bomb Unit, United States Military Weapons.

4 Defense Mapping Agency, United States Military. 
a Glock 26 is good enough for them. Golly-gee, I wonder where in the world our kids are getting the idea that violence is an acceptable method of resolving disputes? Violence has no place in either foreign or domestic policy and certainly no place in our homes, schools, or streets. Even our pop culture has taken on violent tones: the war on drugs (certain drugs that is), the war on hunger, the war on poverty. Perhaps we should declare a war on war. War is violence-violence in its purest and most horrific form. We turn it into an advertising slogan and then stumble around half dazed wondering where in the world Little Billy is picking up his nasty habits.

It is time to take off the blinders and have a long hard look at the world we are creating, if not by active design then certainly by apathetic indifference. We need to figure out a way to mold a society that prizes compassion above all else while at the same time receiving real-time twenty-four-bit colour images of every cruelty and disaster on the planet. The one thing we defiantly and definitively do not need to do is "get over our squeamishness about killing children," or anyone else for that matter. Personally, I think we would be better off with a heaping plate of squeamishness over the concept of killing anyone.

Perhaps if we stop admiring, condoning, rationalizing, and excusing violence then our kids might start to understand that violence is not acceptable. This is a very difficult message to get across when we are saturated by images of the Rodney King beating, the standoffs at Waco and Ruby Ridge, the World Wrestling Federation, and that ubiquitous vulture of "LIVE ACTION NEWS." We send a half-hearted message that violence is wrong: "Damn, Martha! Did you see the way his head turned into a pink mist when the sniper got him Sheeeeit!" Then when Little Billy goes postal we blame the damn video games. Really? Keep telling yourself all that crap and perhaps you won't have to look at yourself too long or too hard.

John MacKenzie is serving a life sentence, and is currently incarcerated at Mission Institution. He can be contacted at Box 60, Mission, British Columbia V2V 4L8, Canada. 